\title{
QUESTÕES DE GÊNERO E SEXUALIDADE PARA TODAS/TODOS: DISCUSSÃO E INCLUSÃO
}

\author{
GENDER AND SEXUALITY ISSUES FOR EVERYBODY: DISCUSSION AND INCLUSION
}

https://orcid.org/0000-0003-1030-0851 Jéssica Gomes das Mercês Costa A

(i) https://orcid.org/0000-0002-3929-7687 Patrícia Machado Moreira ${ }^{\text {B }}$

${ }^{\text {A }}$ Universidade Estadual do Sudoeste da Bahia (UESB), Vitória da Conquista, BA, Brasil

${ }^{\mathrm{B}}$ Secretaria Municipal de Educação (Smed), Vitória da Conquista, BA, Brasil

Recebido em: 07 out. 2021 | Revisões Requeridas em: 30 nov. 2021 / Aceito em: 03 jan. 2022

Correspondência: Jéssica Gomes das Mercês Costa (jessicaa.merces@ hotmail.com)

\section{Resumo}

Este artigo tem como objetivo discutir as questões de gênero e sexualidade associadas à inclusão de pessoas com deficiência visual, a partir de um jogo didático realizado com estudantes de Licenciatura em Ciências Biológicas da Universidade Estadual do Sudoeste da Bahia (UESB). Além disso, levantamos o debate sobre a necessidade de discutir a diversidade e diferença no âmbito da formação inicial dos professores de Ciências. Nesse sentido, a pesquisa contou com dois momentos: o primeiro foi o processo de construção do jogo didático inclusivo; e o segundo momento se caracterizou pela discussão acerca da jogabilidade desse material didático e da importância desta temática na formação inicial docente, através da técnica de grupo focal. Discutir sobre as diferenças (físicas, sexuais, de gênero etc.) na escola, especialmente com deficientes visuais, é buscar uma transformação na sociedade, a fim de que haja inclusão plena no espaço físico escolar, a partir de uma educação adequada e adaptada a todas/todos. Ao final, conclui-se que apesar dos avanços legais e da maior visibilidade do movimento de inclusão, ainda há uma lacuna na formação inicial docente que precisa ser preenchida com temáticas que abranjam as diferenças entre os sujeitos, resultando em práticas pedagógicas que compreendam e atendam às diferenças.

Palavras-chave: Ensino de Ciências; Deficiência visual; Formação docente; Jogo didático.

\section{Abstract}

This paper aims to discuss gender and sexuality issues related to the inclusion of visually impaired people, using a didactic material which was applied with biology graduate students from Universidade Estadual do Sudoeste da Bahia (UESB). Besides that, we debate about the necessity of discussing diversity and the difference in the initial teacher education. Thereunto, this research was developed in two steps, the first was the construction process of the inclusive didactic material; while the second moment was characterized by the discussion about the playability of this teaching material and the importance of this issue in initial teacher education, using the focus group technique for data collection. Discussing differences (physic, sexual, gender, ethnic, race, etc.) in school is to seek a transformation in the society, to establish true inclusion at the school, focusing on an adequate and adapted education for everybody. Despite legislative improvements and the highlight in the inclusion movement, there is still a gap in the initial teacher education that needs to be filled up with discussions about the differences to a praxis that understands and fulfills the differences.

Keywords: Science Teaching; Visual Impairment; Initial Teacher Education; Didactic Material. 


\section{Introdução}

A práxis ${ }^{\mathrm{i}}$, isto é, a reflexão sobre a prática possibilita que as singularidades do cotidiano escolar sejam percebidas. Singularidades estas que, em muitos casos, não são consideradas graças a uma execução mecânica do fazer docente, na qual não há reflexão sobre as vivências de professores e estudantes no cotidiano da escola. Ser sensível as particularidades que formam os indivíduos - físicas, psíquicas, morais e afetivas - permite à professora/ao professor ${ }^{\mathrm{ii}}$ utilizar a sua prática para promover a inclusão, a formação e a aprendizagem.

Em nossa configuração social é comum observarmos no dia a dia da escola que a exclusão acontece a partir de motivos variados e de diferentes formas, envolvendo as questões de raça, classe, cultura, gênero, sexualidade, atributos físicos etc.. Isso significa dizer que ela se manifesta de maneiras diversas, através do isolamento social, violência física ou psicológica, etc. Por ser um tema recorrente, a exclusão da outra/do outro deve ser um tema analisado e discutido tanto na formação docente quanto na prática pedagógica (COSTA; CARMO, 2019).

A escola é uma instituição importante no enfrentamento da problemática supracitada, pois, nesse ambiente é possível discutir e desenvolver experiências inclusivas. Vale lembrar que a perspectiva inclusiva tem como uma de suas ideias principais a defesa de que a sociedade deve fornecer condições para que todas e todos, independentemente dos aspectos subjetivos ou das necessidades especiais, sejam sujeitos ativos nela (ALVES; DUARTE, 2005).

Dentre os elementos que permeiam a existência humana estão as questões de gênero e sexualidade. Estas atravessam o ambiente escolar, visto que é um local de socialização dos sujeitos e de suas particularidades e, em diversos casos, tais particularidades fogem dos padrões estabelecidos. Assim, estudantes “[...] que não se encaixam em padrões ditados pela heteronormatividade tendem a sofrer diversos tipos de violências no ambiente escolar" (COSTA; CARMO, 2019, p. 5). Apesar destes temas serem inerentes à vida humana, as instituições de ensino demonstram despreparo em lidar com as questões de gênero e sexualidade. Muitas professoras e professores dizem não estarem preparadas/preparados para incentivar tais discussões em sala de aula e, em função disso, as educandas e educandos reprimem suas dúvidas, angústias e sentimentos, se sentem deslocadas/deslocados no ambiente escolar e estranhas/estranhos em seus próprios corpos, corpos estes reprimidos pela norma hegemônica imposta socialmente e reproduzida pela e na escola (BENTO, 2013).

A reprodução da normatividade pela escola, ou seja, as cobranças para que todos se encaixem nos padrões hegemônicos pré-determinados, em muitos casos, é uma exigência vinda 
do seio familiar. É importante enfatizar que muitos responsáveis esperam desta instituição (a escola) uma posição conservadora e de correção que esteja em acordo com os valores hegemônicos (COSTA; CARMO, 2019). Para Louro (2000), a escola atua como um ambiente de disciplinarização dos corpos, moldando-os para ações intelectuais e desconsiderando outras singularidades da vida.

Entre as formas de exclusão que devem ser enfrentadas no ambiente escolar, chamamos a atenção para aquela direcionada às pessoas com deficiência. Existem diversos discursos que estereotipam pessoas com deficiência visual, principalmente no que diz respeito à expressão da sexualidade é "[...] como se a deficiência anulasse o desejo" (PAULA; REGEN; LOPES, 2005, p. 23). As questões de gênero e sexualidade fazem parte da vida humana, independente do indivíduo ser deficiente visual ou normovisual. Entretanto, por serem construções sociais existem inúmeras variáveis que envolvem a vivência destas questões, no caso das pessoas com deficiência visual a questão física não compromete o desenvolvimento sexual e expressão de gênero, mas os mitos e limitações psicológicos e sociais podem afetar negativamente (MAIA, 2011).

Por isso, a escola deve ser um lugar democrático, no qual todas/todos as/os agentes escolares possam contribuir igualitariamente para o enfrentamento às violências (hooks, 2013). E a sala de aula é o ambiente propício para cumprir o artigo $5^{\circ}$ da Constituição Federal que afirma que todas as pessoas são iguais e que a discriminação baseada em deficiência deve ser combatida (BRASIL, 1988). Portanto, é importante criar mecanismos para efetivar a igualdade e realizar o processo de inclusão, sobretudo das pessoas com deficiência e/ou que sofrem discriminação. Sobre este assunto, Alves e Duarte apontam a necessidade de

[...] construir uma sociedade capaz de promover a participação social concreta de seus indivíduos. A deficiência visual acarreta, para o indivíduo, uma grande perda de informações decorrente das reduzidas oportunidades de interação com o meio e com as pessoas que o rodeiam (ALVES; DUARTE, 2005, p. 231).

Como introduzido no trecho anterior, nosso foco se volta para a deficiência visual, que segundo o decreto ${ }^{\circ} 5.296$, de 2 de dezembro de 2004, se caracteriza legalmente como

c) deficiência visual: cegueira, na qual a acuidade visual é igual ou menor que 0,05 no melhor olho, com a melhor correção óptica; a baixa visão, que significa acuidade visual entre 0,3 e 0,05 no melhor olho, com a melhor correção óptica; os casos nos quais a somatória da medida do campo visual em ambos os olhos for igual ou menor que 60o; ou a ocorrência simultânea de quaisquer das condições anteriores (BRASIL, 2004 , artigo $\left.5^{\circ}, \S 1^{\circ}, c\right)$. 
Além de definir as deficiências, o decreto supracitado também regulariza vários direitos, entre eles estão o direito ao ensino regular e à acessibilidade. Entretanto, em algumas escolas as alunas e os alunos com deficiência visual só têm garantido o direito à matrícula nas classes regulares, faltando as demais assistências como infraestrutura adequada e profissionais especializados para o atendimento a essas crianças e adolescentes. Além do mais, atentamos para o fato de não haver nas licenciaturas uma formação adequada para lidar com a diversidade humana no cotidiano escolar (SILVA; LANDIM; SOUZA, 2014). Ressalte-se que as lacunas da formação docente não se resumem à abordagem das deficiências, visto que alguns temas considerados complexos, como gênero e sexualidade, muitas vezes não são debatidos durante a formação, sendo apresentados de maneira simplista atrelada somente as questões fisiológicas (SIQUEIRA; OLIVEIRA; BRAGA, 2005).

Dessa forma, discutir sobre os corpos e suas deficiências na escola é buscar uma transformação na sociedade, a fim de que as alunas e os alunos tenham uma inclusão verdadeira no espaço físico escolar, para uma educação adequada e adaptada às particularidades. Diante da lacuna na formação inicial, as professoras e professores precisam se desdobrar para adequarem o planejamento, direcionando-o às subjetividades de suas/seus estudantes. Todavia, a elaboração de estratégias é dificultada, pois

[...] os conteúdos de informação sobre as necessidades educativas especiais são frequentemente inexistentes ou pouco direcionados para a solução de problemas concretos de planejamento, intervenção e avaliação que o profissional possa vir a encontrar. Os profissionais de apoio também são inexistentes, e o apoio educativo é fornecido por docentes que não são da área disciplinar (ALVES; DUARTE, 2005, p. 233).

É interessante ressaltar que os processos fisiológicos são os mesmos nos corpos das alunas/dos alunos videntes e com deficiência visual, portanto, se é necessário às primeiras/aos primeiros o conhecimento das questões de gênero, às segundas/aos segundos também são discussões pertinentes, afinal, ambas/ambos chegarão à puberdade e todos os questionamentos que envolvem este período (BEZERRA; PAGLIUCA, 2010; PAULA; REGEN; LOPES, 2005). Sabemos como a sociedade cultua o corpo dentro dos padrões estabelecidos hegemonicamente, atribuindo a ele grande importância graças às cobranças em relação às características físicas. Assim, muitas vezes, entre os adolescentes o diferente acaba se tornando intolerável (PAIXÃO, 2013). Como apresentado por Oliva (2016) amiúde a pessoa com deficiência visual se inferioriza diante de pessoas normovisuais, aquelas que não possuem deficiência visual, 
considerando que "[...] o padrão de sucesso ainda é associado ao modelo de perfeição" (idem, p. 500).

Ademais, no tocante às pessoas com deficiência visual, elas são inferiorizadas pela família em relação às questões de sexualidade e rotuladas como assexuadas. Mas, advertimos que a superproteção dada pela família pode dificultar futuras relações afetuosas e sexuais (BEZERRA; PAGLIUCA, 2010), e, consequentemente, gerar indivíduos reprimidos. Além disso, a superproteção pode levar as pessoas com deficiência visual a um isolamento social, gerando vulnerabilidade e carência afetiva (MAIA, 2011; PAIXÃO, 2013). Nesse contexto, é no ambiente escolar que alguns casos de abusos e exploração de jovens e adolescentes com deficiência serão revelados. Porém, tais situações demoram para se tornar evidentes devido ao isolamento forçado e a invisibilidade da pessoa com deficiência (FERREIRA, 2008). Segundo Maia (2006, p. 32) “[...] quando julgamos um deficiente pelo seu rosto corremos um sério risco de desconsiderar todas as possibilidades que existem, em relação à sua sexualidade, de humanização, cidadania e plena inclusão social", o que confirma a ideia de que a sexualidade das/dos jovens com deficiência visual é reprimida e, como consequência, elas/eles desconhecem o próprio corpo e não sabem definir seus sentimentos.

As poucas de discussões voltadas para a diversidade no âmbito escolar não é irrefletida, uma vez que nos dias atuais tem se atenuado as disputas para controlar do que acontece nas escolas. Por um lado, é possível perceber a movimentação de grupos associados a uma ideologia neoliberal que busca o emprego de uma metodologia empresarial para reger a escola; por outro lado, encontramos grupos neoconservadores que buscam a repressão moral e a elevação de valores e ideais hegemônicos, tendo como base a família tradicional e a religião (BORBA; ANDRADE; SELLES, 2019, grifo dos autores).

Diante disso, enfatiza-se a importância de conscientizar docentes e discentes sobre a necessidade de respeitar a realidade da outra/do outro e suas limitações enquanto pessoa, pois esse processo cultural e social leva à reflexão sobre a dignidade humana. Nesse sentido, é fundamental quebrar tabus e ensinar nas aulas sobre as questões de gênero, sexualidade e diversidade de corpos, para que estas educandas/estes educandos consigam refletir sobre “[...] o reconhecimento do 'outro', daquela ou daquele que não partilha dos atributos que possuímos [...]" (LOURO, 2000, p. 9, grifo da autora).

Em tal conjuntura é dever e papel da escola desenvolver estratégias (aulas, palestras, jogos, teatro etc.) que possam incluir todas e todos no processo educativo, além de levar estudantes a refletirem sobre a imposição da heteronormatividade e do patriarcado e buscar 
meios de esclarecer que tais imposições podem e devem ser desconstruídas. Vale ressaltar que, segundo Louro (2000), propagar como norma a sexualidade branca, classe média e heterossexual é promover uma educação sexual heteronormativa que promove a exclusão e normalização. Tal abordagem fortalece o sistema social patriarcal, o qual promove a ideia de que os homens com características heteronormativas ocupam o poder por direito, dessa forma, pessoas não brancas, que não são homens heterossexuais ou que apresentam alguma deficiência são inferiorizadas ou invisibilizadas na hierarquia socialmente estabelecida.

Considerando o atual contexto estabelecido no país, pensar em desconstruir preconceitos existentes na escola, trabalhar em uma pedagogia inclusiva e preparar a instituição para abordar as questões de gênero e sexualidade, além de quebrar os paradigmas da heteronormatividade e do regime patriarcal, é uma forma de resistência e intervenção para melhorar a vivência em sociedade.

É responsabilidade dos agentes escolares criar situações de aprendizagem nas quais se possa discutir as questões de gênero e sexualidade que incluam as pessoas com deficiência visual. Para além das questões fisiológicas, é importante discutir a desigualdade de gênero e as discriminações sofridas por grupos minoritários (PAIXÃO, 2013) que são sofridas duplamente por indivíduos com deficiência. Assim, a partir da necessidade de se produzir materiais para fomentar as discussões de gênero e sexualidade, produzimos um jogo didático que, para além do debate dessas temáticas, possibilitasse o processo de inclusão das pessoas com deficiência visual e sua aprendizagem. Além disso, buscamos propor a reflexão sobre o desenvolvimento de estratégias didáticas inclusivas na formação inicial de professores.

Quanto à organização, este artigo foi estruturado em dois eixos: a) no primeiro, relatamos o processo de produção de um material didático inédito que possibilite a discussão das questões de gênero e sexualidade com estudantes videntes e com deficiência visual, conjuntamente; b) no segundo, abordamos as reflexões e avaliações adquiridas através do debate com uma turma de graduandos, sobre a funcionalidade do jogo didático. Por fim, apresentamos nossas considerações finais.

\section{A estrutura do jogo didático - desafios iniciais}

O jogo didático Trilhando Conhecimentos sobre Gênero e Sexualidade (Figura 1) foi construído no contexto de um Projeto de Intervenção, trabalho necessário para obtenção do título de especialista em gênero e sexualidade pela Universidade Federal da Bahia (UFBA). 
Figura 1: Tabuleiro e elementos do jogo Trilhando Conhecimentos sobre Gênero e

\section{Sexualidade}

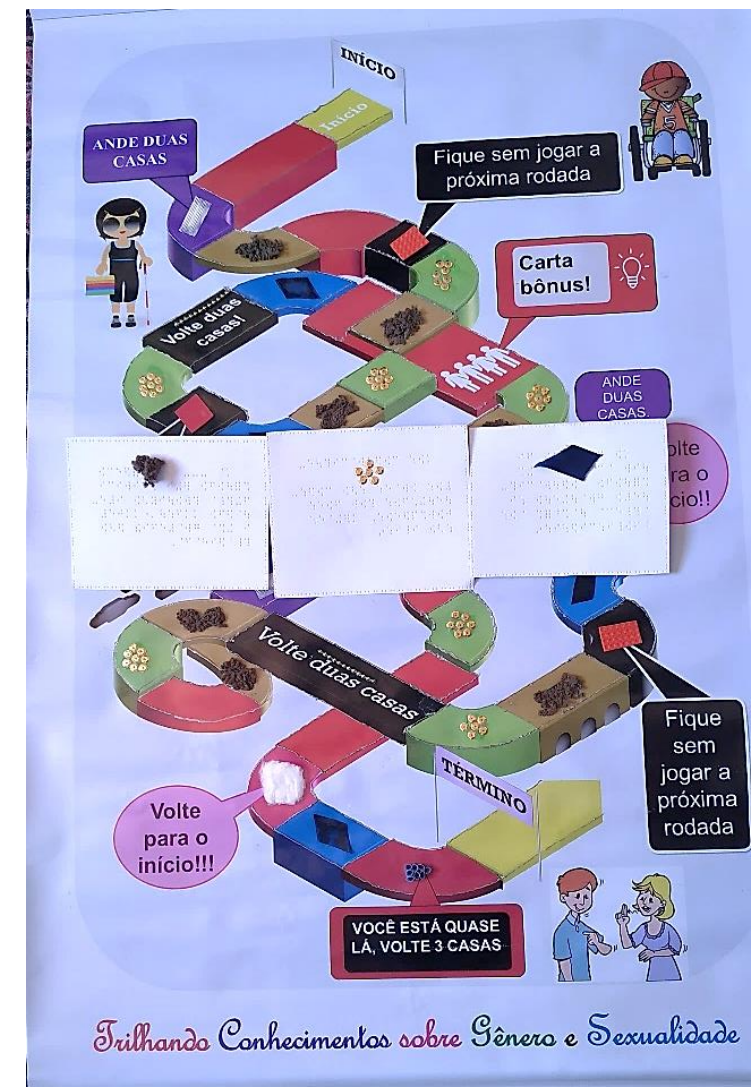

Fonte: Arquivo digital das autoras, 2020.

$\mathrm{Na}$ imagem anterior está a representação do trajeto em alto-relevo da trilha, apresentando diferentes texturas com lã verde musgo, lantejoula amarela e cetim azul. Também estão exemplificadas três cartas do jogo estão sobre o tabuleiro, escritas em Braille e com a textura referente às respectivas casas da trilha. Jogos didáticos são importantes instrumentos educacionais, pois incentivam o aprendizado, bem como prazer pelo jogo e interação social. Diante disso, é interessante ressaltar que

[...] o foco na dimensão social da aprendizagem, aliado à remoção de barreiras e às estratégias que favoreçam o uso coletivo de materiais e a cooperação, permitirá ao professor utilizar recursos tateáveis/visuais/auditivos e organizar a sala de aula de modo que ela seja acessível a todos os alunos (LAPLANE; BATISTA, 2008, p. 225). 
Partindo dessa premissa, afirmamos que as atividades lúdicas abrem espaço para a convivência e inclusão. Assim, ao fazer uso de tais ferramentas a professora/o professor se propõe a construir um ambiente de interação entre as/os estudantes, além de proporcionar o diálogo e construção de conhecimentos. Para hooks (2013, p. 56) é necessário fazer da “[...] aula um contexto democrático onde todos sintam a responsabilidade de contribuir".

Pensando no contexto de uma sala de aula de ensino regular, na qual encontram-se pessoas com deficiência visual, é interessante que a professora/o professor leve em consideração que um dos estímulos indispensáveis para que estas pessoas aprendam é o toque (LAPLANE; BATISTA, 2008). Dentro da temática discutida nesse artigo, questões de gênero e sexualidade, podemos inferir que a cultura sexual de massa é basicamente visual (revistas, vídeos, imagens ou livros). Nesse sentido, é importante ter consciência disso ao abordar tal temática com deficientes visuais (PAIXÃO, 2013), para não cometer equívocos ao discuti-la fazendo uso somente de artifícios visuais, desconsiderando a importância do toque para o aprendizado das pessoas com deficiência.

Diante disso, afirmamos que a elaboração do jogo didático se deu com base em dois requisitos básicos, primeiro, foi planejado de modo que sirva como um elo entre a aprendizagem dos conteúdos das questões de gênero e sexualidade e a ludicidade; segundo, teve como foco ser acessível às pessoas com deficiência visual. Portanto, a aluna/o aluno poderá em conjunto com suas/seus colegas competirem em uma trilha do conhecimento acerca da referida temática, na qual a cada avanço surgirão perguntas ou contextos a serem debatidos. Além disso, procuramos dar autonomia, durante o jogo, para a aluna ou o aluno com deficiência visual tenha a possibilidade de jogar os dados. Destaque-se que os dados foram adaptados sob orientações da Associação Conquistense de Integração do Deficiente (Acide), a fim de que se tornassem acessíveis foram modificados, uns com cola relevo 3D e outros pinos foram adicionados para criar o relevo, além disso, a/o estudante poderá também ler as cartas com as perguntas, visto que as mesmas estão escritas de forma digitada em fonte tamanho 28 ou maior e em Braile, de modo que as/os estudantes poderão reconhecer e acompanhar o trajeto da trilha, que está em alto-relevo e com legenda para cada uma das texturas.

É relevante destacar que ambas as autoras do jogo didático são videntes, por isso, ao iniciar o desenvolvimento desta pesquisa, lidamos com uma série de indagações e situações que não compreendíamos, por esse motivo muitas das projeções feitas a princípio foram submetidas a uma readequação, pois não eram acessíveis ou inclusivas. Com isso, foi imprescindível que 
consultássemos pessoas com deficiência visual, afinal, o nosso objetivo era desenvolver um recurso pedagógico eficaz que atendesse ao propósito de acessibilidade para pessoas com deficiência visual. Assim, contamos com o auxílio da Associação Conquistense de Integração do Deficiente (Acide), no qual alguns membros fizeram diversas intervenções e uma das colaboradoras da associação nos auxiliou na digitação em braile, nos modelos dos dados, na testagem do material etc.

Ao longo da produção foi necessário que reorganizássemos tamanhos, formas e outros elementos para adequar o jogo didático seguindo a lógica de que a sociedade é quem deve se reestruturar para atender as demandas das/dos suas/seus integrantes, assim todas e todos podem participar plenamente da vida em sociedade (ALVES; DUARTE, 2005). E foi nesse contexto que produzimos o jogo didático Trilhando Conhecimentos sobre Gênero e Sexualidade, o qual consiste em 39 cartas digitadas em braile, um tabuleiro impresso em banner (no qual está a trilha em alto relevo com as casas correspondentes às cartas com variadas texturas), dados adaptados e peões com diferentes texturas. Para tanto, buscamos seguir as recomendações de Laplane e Batista (2008), os quais incentivam que as atividades em grupo sejam baseadas nas ideias do desenho universalii ${ }^{\text {iii }}$ que os jogos de tabuleiro se caracterizem como um material não poluído, com informações táteis e visuais.

\section{Reflexões sobre gênero, sexualidade e inclusão sob a ótica dos graduandos}

Em termos metodológicos, esta é uma pesquisa de cunho qualitativo por meio da qual as pesquisadoras se inserem no campo de investigação para dialogar com os sujeitos, considerando suas subjetividades. A produção de dados junto aos sujeitos da pesquisa foi através da técnica de pesquisa grupo focal, considerando a afirmação de Minayo (2014, p. 193) que "É possível também que o investigador escolha as discussões em grupo como o instrumento principal da abordagem da pesquisa". Os trabalhos desenvolvidos com o grupo se deram em dois momentos: primeiramente, foi realizada a aplicação do jogo didático, para que os sujeitos conhecessem a funcionalidade deste material; o segundo momento foi a discussão acerca da produção didática que lhes foi anteriormente apresentado. Em ambas etapas foram feitas anotações e/ou gravações das falas e expressões dos sujeitos pesquisados.

Para a produção de dados, optamos pelo ambiente acadêmico como campo empírico tendo como sujeitos da pesquisa as/os estudantes de uma turma de Licenciatura em Ciências Biológicas da Universidade Estadual do Sudoeste da Bahia (UESB). Ressalte-se que na turma 
escolhida, todas e todos estudantes eram videntes. Ao entrar em contato com os professores da disciplina (na época contava com duas turmas) somente um deles se disponibilizou a participar, em nenhuma das turmas que da disciplina Temática em Sexualidade haviam deficientes visuais. Por isso, destaca-se a importância das/dos deficientes visuais associadas/associados da Acide no processo de produção do jogo didático.

Diante da ausência de pessoas com deficiência visual nas turmas, refletimos sobre as lacunas ao longo da história escolar que dificultam o acesso destas pessoas no ensino superior, considerando as barreiras físicas, de aprendizagem e participação enfrentadas por elas (OLIVA, 2016). De acordo com Laplane e Batista (2008) ainda que a deficiência física não seja um empecilho para a aprendizagem, existe uma série de fatores (detecção e intervenção precoce, assistência à criança e família, formação dos profissionais docentes e disponibilidade de recursos que incentivem o interesse e participação de deficientes visuais nas atividades escolares) que podem inviabilizar a trajetória escolar.

Após a produção do jogo didático, o mesmo foi aplicado na turma da disciplina "Temáticas em Sexualidade" que o professor e as/os estudantes se dispuseram a participar e, em seguida, desenvolvemos uma roda de conversa com as graduandas/os graduandos e o professor da disciplina acerca da experiência com o material didático, como parte do grupo focal incentivando a participação de todos os presentes (MINAYO, 2014). No primeiro momento, foram apresentadas e assinadas as autorizações necessárias (Termo de Consentimento Livre e Esclarecido - TCLE) e enfatizada a relevância da participação de todas/todos que estavam presentes. A partir disso, com o consentimento de todas/os, as falas dos sujeitos foram gravadas.

O jogo didático foi apresentado à turma, que foi dividida em dois grupos. Em seguida, solicitamos que as regras do jogo fossem lidas por um sujeito da pesquisa e deu-se início a partida. Conforme o jogo avançava as discussões sobre as perguntas e as interações entre as/os participantes aumentavam, ainda que no início a maioria tenha apresentado timidez e receio em participar. Isso é corroborado por algumas falas e atitudes das graduandas/dos graduandos nesse primeiro momento, visto que não tomavam iniciativa e diziam "vai você primeiro", "você pode jogar o dado". Além disso, nas três primeiras cartas retiradas os sujeitos demonstraram insegurança para respondê-las e ampliar a discussão. Ou seja, as respostas foram dadas rapidamente e sem muita ênfase.

Nesse contexto, foi perceptível a resistência ao debater as questões de gênero e sexualidade, ainda que seja em uma disciplina que aborde exatamente tais temáticas. 
Analisando as primeiras interações com o jogo, pudemos observar que foram rápidas, sem um aprofundamento das problemáticas propostas, o que nos possibilita fazer um paralelo com a maneira que como estas questões são tratadas nas salas de aula, onde as professoras/os professores buscam negá-las nas discussões com as/os estudantes (PAIXÃO, 2013). Quanto ao receio destas/destes graduandas/os em expor suas opiniões, pode estar enraizado na ideia de complexidade da temática que é constituída por diversas dimensões e subjetividades, as quais tornam difícil a compreensão deste tema (SIQUEIRA; OLIVEIRA; BRAGA, 2005).

Temáticas herméticas como as questões de gênero e sexualidade, teoria da evolução, questões étnico-raciais, corpo humano e saúde, são revestidas por um conservadorismo exacerbado que envolve nossa sociedade, gerando uma série de preconceitos e estereótipos (BORBA; ANDRADE; SELLES, 2019), e a abordagem destes temas se tornam ainda mais complexos quando o público-alvo são pessoas com deficiência devido aos estereótipos de inferiorização que a sociedade estipula a estes indivíduos. Então, a depender dos valores individuais construídos por essas professoras/esses professores em formação e, também, de como elas/eles se relacionam com as diferenças, vai influenciar em quão confortável será a discussão desta temática e a disponibilidade para desconstruir e reconstruir conceitos. Para essas pessoas, quanto maior e mais frequente o contato e reflexão crítica em relação às identidades sociais construídas, maior será o seu posicionamento em favor das subjetividades e renúncia à submissão a normatividade (SIQUEIRA; OLIVEIRA; BRAGA, 2005).

Como já mencionado, ao longo do progresso na trilha do jogo didático, as graduandas/os graduandos começaram a apresentar um maior interesse em participar, confirmado através de falas como, vamos poder interagir e complementar com o outro grupo? (Grupo A) e posso complementar a fala do colega? (Grupo B).

Para além de simplesmente demonstrar interesse, elas/eles realmente começaram a se aprofundar nas problemáticas que foram surgindo, auxiliando-nos no aprimoramento do jogo didático. Por exemplo, em determinada carta havia a seguinte afirmação "O é dado pelas características biológicas: nasce-se macho ou fêmea da espécie humana”. Ao invés de simplesmente completar a afirmação com o termo correto (sexo biológico), surgiram inquietações sobre a exclusão dos indivíduos intersexo, aquelas/aqueles que podem desenvolver, naturalmente, ambas características sexuais biológicas.

Durante o jogo, outra interação que merece destaque é

Grupo B: Carta do jogo: Quais são os tipos de violência que podem ser sofridas por preconceito de gênero ou sexualidade? [...] depois de uma troca de informação com 
os colegas do grupo e professor, chegamos à conclusão que, no atual contexto social e político, podemos observar o quanto as violências vêm crescendo, principalmente a homofobia e feminicídio.

Com isso, de forma a acrescentar na discussão, o Grupo A apresentou algumas contextualizações referentes a experiências pessoais e na família. Ao final da discussão os dois grupos concordaram que a disseminação do ódio é o principal agente de preconceito nas questões de gênero e sexualidade. Tal conclusão é corroborada por Costa e Carmo (2019) ao afirmarem que a violência é pauta vigente nos estudos relacionados a gênero e se faz presente desde os estudos curriculares até as interações sociais na escola.

A questão da família também se apresenta nos debates sobre gênero e sexualidade e não foi diferente durante o jogo, ao discutir a seguinte carta "É importante ampliar os conhecimentos desse tema para além do que é aprendido na família?”. Sobre esse assunto, os grupos teceram os seguintes comentários:

Grupo A: O mais que importante é ensinar, pois a grande maioria não sabe nada a respeito das questões de sexualidade e gênero ou simplesmente ignora essa informação, devido ao seu próprio preconceito, deixando assim seu filho e sua filha sem a devida informação.

Grupo B, complementando a resposta do grupo A: Além disso muitos pais acham que a escola tem a obrigação de manter os filhos (a) informados, mas, esses mesmos pais são contra o assunto na escola, ou seja, dificulta a vida de todos.

Como podemos notar, os dois grupos levantaram argumentos importantes no debate da relação da família com essa temática. Na primeira fala supracitada podemos perceber que ignorar é a forma utilizada por muitas famílias para lidar com as questões de gênero e sexualidade. No estudo realizado por Paixão (2013, p. 245) o relato de uma professora ratifica isso, “[...] os responsáveis justificam que não sabem falar sobre estes assuntos e nem querem tentar. A família transfere a responsabilidade da orientação sexual para a escola”. A dificuldade em conversar sobre as questões de gênero e sexualidade pode estar ligada ao fato de haver uma lacuna de conhecimento por parte dos pais e/ou responsáveis e ser reflexo de suas próprias vivências enquanto adolescentes (BEZERRA; PAGLIUCA, 2010). Em outros casos, quando o diálogo ocorre, ele é pautado somente em informações de caráter físico, relacionado aos órgãos genitais, gravidez e doenças sexualmente transmissíveis (idem).

Enquanto isso, a fala supracitada do Grupo B remete à contradição apresentada por muitas famílias que acreditam ser responsabilidade da escola dialogar sobre essa temática, ao 
mesmo tempo não aprovam que o debate seja feito. Isso explicita que, segundo algumas concepções, as questões de gênero e sexualidade devem se manter restritas aos conhecimentos meramente anatomo-fisiológicos, desconsiderando os sentimentos, identidades, desigualdades, preconceitos e todos as subjetividades as envolvem. Principalmente, no que diz respeito a tal abordagem com pessoas com deficiência visual que a família "ao se deparar com a deficiência, a tendência é prolongar a infância e manter os filhos sob dependência" PAULA; REGEN; LOPES, 2005, p. 109) ignorando os aspectos de gênero e sexuais que envolvem o indivíduo.

Determinados indivíduos se posicionam contra discussões reais e aprofundadas dessas pautas na escola e se justificam em nome de valores morais da família e da religião (BORBA; ANDRADE; SELLES, 2019), um posicionamento inteiramente conservador que é permeado de preconceitos e que invisibiliza os corpos ditos diferentes. Bezerra e Pagliuca (2010) afirmam que quando não há diálogos sobre gênero e sexualidade na família e tampouco no ambiente escolar, as pessoas com deficiência visual buscam informações com suas amigas/seus amigos, muitas delas pessoas normovisuais, o que as influenciam a tentar atuar de forma similar às/aos videntes e se deparam, em alguns casos, com a barreira da falta de visão.

Além das inferências feitas ao longo da aplicação do jogo didático, muitas colocações interessantes foram postas no segundo momento do jogo. As professoras e professores em formação pautaram alguns elementos como: a importância da inclusão no jogo; o fato de ter um número de cartas que faz com que as discussões não sejam as mesmas ao longo da trilha; a linguagem acessível que amplia o público-alvo, tudo isso traz informações que todas/todos devem saber. Portanto, é uma forma de inserir qualquer pessoa nas discussões.

A respeito das discussões suscitadas, a seguir trazemos algumas falas interessantes apresentadas por elas/eles:

Aluno 1: [...] é difícil você ver uma discussão de sexualidade e gênero que abrange deficiente visual.

Aluna 2: [...] é bom porque todo mundo se sente inserido, tendo deficiência ou não, né? Ele consegue fazer todo mundo participar independente de uma deficiência física ou não.

Aluna 3: [...] eu achei muito interessante, né? Porque é um material bem lúdico traz uma opção bem legal de você trabalhar [...] nas casas as crianças não têm abertura pra discussão desses temas, aí elas vêm pra escola e tem esse material que além de inclusivo é uma coisa legal. 
A característica do jogo didático que mais chamou a atenção dos sujeitos da pesquisa foi a inclusão. Alguns relataram que nem mesmo na disciplina voltada para o estudo das deficiências eles tiveram acesso a materiais que auxiliassem o processo de ensinoaprendizagem das futuras alunas e alunos com deficiência. O incentivo dessas discussões ainda na graduação é essencial, pois pode impedir que o reconhecimento da existência de estudantes com deficiência visual nas escolas aconteça somente ao se deparar com elas/eles na prática docente (LAPLANE; BATISTA, 2008; SILVA; LANDIM; SOUZA, 2014). E a exemplificação de recursos didáticos que podem ser utilizados no cotidiano escolar, que para além de promover a inclusão possibilita o aprendizado, é uma forma de incentivar estas graduandas/estes graduandos a pensarem novas estratégias pedagógicas.

A ludicidade do material também demonstrou ser um ponto positivo. Afinal, utilizar o lúdico para lecionar é uma maneira de aprender e, consequentemente, de ensinar que envolve todas/todos, ademais, as alunas e alunos com deficiência visual precisam de um estímulo para a participação ativa e interação social. Dessa forma, optar pelo lúdico é uma forma de atrair a atenção destas/destes e evitar a marginalização no ambiente escolar (OLIVA, 2016).

As contribuições do professor da disciplina mostraram que o recurso didático permite a inclusão e interação dos grupos, possibilitando que essa discussão ocorra dentro de uma perspectiva mais cognitiva, ou seja, ela não se limita a memorização de termos técnicos ou respostas prontas, a construção da discussão se dá por intermédio da partilha de narrativas, raciocínios etc. Isso significa dizer que o debate se complementa a partir das interferências de cada pessoa presente, porque, às vezes, determinadas questões não são do conhecimento de todas/todos, mas o envolvimento do grupo permite que o conhecimento seja compartilhado.

Outra consideração relevante apresentada pelo professor foi a sensibilidade de pensar na autonomia da/do estudante deficiente. Assim, reafirmamos a importância do sentido do tato para a inclusão de estudantes cegas/cegos (SILVA; LANDIM; SOUZA, 2014), e ampliamos a discussão com a fala do professor sobre a autonomia da/do estudante deficiente.

Professor: Uma coisa que eu achei importante enquanto contribuição que eu esqueci de falar foi a questão do braile nas cartas de perguntas, e neste processo tem duas coisas que muitas vezes a gente não se atenta, uma coisa é saber que a pessoa é deficiente visual que ela não vai conseguir enxergar, ela vai usar o tátil, né? E a gente, às vezes, pode fazer leitura do seguinte, 'ah não precisa colocar no braile porque ele é cego, mas ele ouve, então outra pessoa poderia estar lendo'. Mas eu acho que tem que ter a oportunidade pra ele participar também do processo de leitura e ter autonomia pra isso, desenvolver a sua interpretação sobre uma pergunta através daquilo que ele pode perceber, que ele pode sentir. Talvez outras pessoas dispensassem, 'não até que o jogo ali bote o que tátil, mas como ele ouve uma pessoa 
pode fazer a pergunta', acho que se está falando de inclusão tem que colocar todas as possibilidades.

A observação feita pelo professor é importante, pois enfatiza a necessidade de dar o máximo de autonomia possível para a pessoa com deficiência visual, nesse sentido, os recursos didáticos devem superar o ouvir (SILVA; LANDIM; SOUZA, 2014). Assim é possível que as/os deficientes visuais se mobilizem para além da passividade e possam agir, pegar, sentir e interferir, ou seja, ser um agente ativo em seu processo de aprendizagem. A inclusão é, portanto, um dos aspectos mais importantes para incentivar a participação das alunas/dos alunos com deficiência. Além do mais, é direito de todas/todos que sejam estabelecidas as condições básicas para a participação e convivência social (ALVES; DUARTE, 2005).

É importante frisar que apesar da legislação garantir a matrícula de alunas e alunos com deficiência nas escolas é necessário que todos os agentes escolares ajam para que ocorram, de fato, os processos de inclusão e aprendizagem destas pessoas (OLIVA, 2016). Entretanto, as lacunas deixadas na formação inicial ou continuada, em relação ao processo de ensinoaprendizagem de pessoas com deficiência visual, gera dificuldades tanto para as/os docentes quanto para as/os discentes deficientes (SILVA; LANDIM; SOUZA, 2014). De acordo com Alves e Duarte (2005), o professor tende a excluir ou invisibilizar os alunos com deficiência, influenciados pela falta de preparo profissional adequado. A respeito deste assunto, a reflexão feita pelo professor para suas alunas e alunos nos ajuda a pensar. Afirmou ele:

Professor: Eu acho que é importante a gente colocar é que mesmo que vocês não tenham efetivamente aplicado no ensino básico, vocês vieram aplicar no ensino da formação de vocês. É muito importante, porque leva os alunos em formação a refletirem sobre a necessidade de que os jogos educativos, o próprio pensamento da inclusão entendendo essa diversidade que é estar na escola. É interessante pensar sobre isso, eu acho extremamente importante que esse aluno em formação participe deste processo. [...] os próprios momentos em que eles não tiveram essa discussão especialmente na disciplina, mas nos próprios eventos que fazem considerações da própria natureza para fortalecer isso. Aí no caso é também para a gente fazer disso uma reflexão que o espaço da sala de aula também é espaço de pesquisa.

Portanto, falar sobre a formação de professores é essencial no que diz respeito ao que se espera da prática pedagógica, principalmente se a expectativa é que a prática supere os ditames do tradicionalismo e conservadorismo. No que tange às questões de gênero e sexualidade, diversas autoras e autores enfatizam que somente através da formação inicial ou continuada adequadas se pode superar os déficits relacionados a abordagem de tais questões na educação (BORBA; ANDRADE; SELLES, 2019; COSTA; CARMO, 2019). 


\section{Considerações finais}

O processo de produção de um material didático é permeado por uma série de construções, desconstruções e reconstruções, visto que em muitos casos, o que idealizamos não se materializa de forma integral, sendo imprescindível a reflexão sobre as mudanças necessárias. Tal experiência se intensificou ao propor a produção de um material didático sobre gênero e sexualidade voltado para pessoas com deficiência visual, visto que nenhuma das autoras possui tal deficiência e não conhece, por meio das vivências, as singularidades que envolvem estes sujeitos. Entretanto, com as contribuições das pessoas cegas da Acide foi possível produzir com êxito um material inclusivo e funcional que alcança o objetivo inicial de promover o debate sobre as questões de gênero e sexualidade no ambiente escolar.

Enfatizamos, assim, a importância da partilha, do diálogo e dos debates nas produções acadêmicas, sobretudo em uma pesquisa de cunho qualitativo como esta, a qual tem como base a interação com os sujeitos. Desse modo, as experiências somadas permitiram a produção de um material didático que além de possibilitar a inclusão de estudantes deficientes visuais, também se torna um facilitador das discussões de gênero e sexualidade, tema considerado tabu e complexo de ser abordado em sala de aula.

Através das discussões realizadas com os diferentes sujeitos ao longo da produção do material físico e das interações com as graduandas e graduandos, ficou mais evidente a movimentação de grupos conservadores que buscam suprimir a diversidade e impedir o debate das questões de gênero e sexualidade seja nas escolas, no seio familiar ou outros locais de interação social, mesmo sendo estas questões inseparáveis da vivência humana. Além disso, observamos que apesar dos avanços na legislação e do movimento de inclusão, ainda há uma lacuna na formação inicial docente que precisa ser preenchida, tanto no que diz respeito às questões de gênero e sexualidade, quanto no que se refere ao desenvolvimento de práticas pedagógicas voltadas para as pessoas com deficiência visual (assim como para as demais deficiências). Nesse sentido, ressaltamos a importância da conscientização nos processos formativos, de novas pesquisas e produção de materiais voltados para essas questões, afinal, para acabar com a invisibilidade é necessário que estas pessoas sejam ouvidas, vistas e consideradas.

Ademais, para enfrentar a invisibilidade é necessário que as minorias tomem os espaços e se mobilizem contra a repressão e contra o silenciamento, pois o respeito só se estabelecerá 
por intermédio do conhecimento. Para uma formação humana e integral das alunas e alunos, elas/eles precisam conhecer o diferente e compreender a diversidade, além de reconhecer que faz parte do ser humano a amplitude de subjetividades. Nesse contexto, a escola é um dos principais ambientes a permitir que o debate aconteça de forma ampla e respeitosa, afinal, através da formação humana e integral dos indivíduos é possível construir uma sociedade mais equânime.

\section{Referências}

ALVES, Maria Luiza Tanure; DUARTE, Edison. A inclusão do deficiente visual nas aulas de educação física escolar: impedimentos e oportunidades. Acta Scientiarum. Humanand Social Sciences, v. 27, n. 2, p. 231-237, 2005. Disponível em:

https://www.redalyc.org/pdf/3073/307324855011.pdf Acesso em: 05 set. 2021.

BENTO, Berenice. Na escola se aprende que a diferença faz a diferença. Revista Estudos Feministas, v. 19, n. 2, 2013. Disponível em: http://www.scielo.br/pdf/ref/v19n2/v19n2a16.pdfAcesso em: 05 set. 2021.

BEZERRA, Camila Pontes; PAGLIUCA, Lorita Marlena Freitag. A vivência da sexualidade por adolescentes portadoras de deficiência visual. Revista da Escola de Enfermagem da USP, v. 44, n. 3, p. 578-583, 2010. Disponível em:

http://www.scielo.br/pdf/reeusp/v44n3/05.pdfAcesso em: 05 set. 2021.

BORBA, Rodrigo Cerqueira do Nascimento; ANDRADE, Maria Carolina Pires de; SELLES, Sandra Escovedo. Ensino de Ciências e Biologia e o cenário de restauração conservadora no Brasil: inquietações e reflexões. Revista Interinstitucional Artes de Educar. Rio de Janeiro, v. 5 n. 2, p. 144-162, mai./ago., 2019. Disponível em: https://www.epublicacoes.uerj.br/index.php/riae/article/view/44845/30450Acesso em: 06 set. 2021.

BRASIL. Constituição da República Federal do Brasil. Brasília, DF: Senado Federal, 1988. Disponível em:

https://www2.senado.leg.br/bdsf/bitstream/handle/id/518231/CF88_Livro_EC91_2016.pdfAc esso em: 05 set. 2021.

BRASIL. Decreto n 5.296 de 2 de dezembro de 2004. Regulamente leis que dá prioridade no atendimento e estabelece normas gerais e critérios básicos para a promoção da acessibilidade das pessoas portadoras de deficiência. Diário Oficial [da] República Federativa do Brasil. Brasília, DF, 2014. Disponível em: http://www.planalto.gov.br/ccivil_03/_ato2004-2006/2004/decreto/d5296.htm Acesso em: 05 set. 2021.

COSTA, Jéssica Gomes das Mercês; CARMO, Edinaldo Medeiros. Gênero na escola: o que dizem as publicações nos periódicos nacionais. In: Seminário Nacional, 7, e Seminário Internacional, 3, Políticas Públicas, Gestão e Práxis Educacional, 2019, Vitória da Conquista. Anais eletrônicos... Vitória da Conquista: UESB, 2019. Disponível em: http://anais.uesb.br/index.php/semgepraxis/article/viewFile/8448/8116Acesso em: 06 set. 2021. 
FERREIRA, Windyz Brazão. Vulnerabilidade à violência sexual no contexto da escola inclusiva: reflexão sobre a invisibilidade dapessoa como deficiência. Revista Iberoamericana sobre Calidad, Eficacia y Cambio en Educación, Madrid, v. 6, n. 2,p. 120-136, 2008.

Disponível em: https://www.redalyc.org/pdf/551/55160210.pdf Acesso em: 09 dez. 2021.

HOOKS, Bell. Ensinando a transgredir: a educação como prática da liberdade. Trad. Marcelo Brandão, São Paulo: WMF Martins Fontes, 2013.

LAPLANE, Adriana Lia Friszman de; BATISTA, Cecília Guarneiri.Ver, não ver e aprender: a participação de crianças com baixa visão e cegueira na escola. Cadernos Cedes, Campinas, v. 28, n. 75, p. 209-227, maio-ago., 2008. Disponível em:

http://www.scielo.br/pdf/ccedes/v28n75/v28n75a05.pdf Acesso em: 06 set. 2021.

LOURO, Guacira Lopes. O corpo educado: Pedagogias da sexualidade. 2. ed. Belo Horizonte: Autêntica, 2000.

MAIA, Ana Cláudia Bortolozzi. Educação sexual e sexualidade no discurso de uma pessoa com deficiência

visual. Ibero-Americana de Estudos em Educação, São Paulo, v. 6, n.3, 2011. Disponível em: https://repositorio.unesp.br/bitstream/handle/11449/125073/ISSN1982-5587-2011-06-03-90101.pdf? sequence=1\&isAllowed=y Acesso em: 03 fev. 2022.

MAIA, Ana Cláudia Bortolozzi. Sexualidade e deficiência. São Paulo: UNESP, 2006.

MINAYO, Maria Cecília de Souza $O$ desafio do conhecimento: pesquisa qualitativa em saúde. 14. ed. São Paulo: Hucitec, 2014.

OLIVA, Diana Villac. Barreiras e recursos à aprendizagem e à participação de alunos em situação de inclusão. Psicologia USP, São Paulo, v. 27, n. 3, p. 492-502, dez., 2016.

Disponível em: http://www.scielo.br/scielo.php?script=sci_arttext\&pid=S010365642016000300492\&lng=en\&nrm=iso Acesso em: 05 set. 2021.

PAIXÃO, Luciano de Pontes. Inclusão de adolescentes deficientes visuais em atividades de orientação sexual: uma proposta inovadora. Revista Contemporânea de Educação, v. 8, n. 15, jan./jul., 2013. Disponível em: https://revistas.ufrj.br/index.php/rce/article/view/1695/1544 Acesso em: 06 set. 2021.

PAULA, Ana Rita de; LOPES, Penha; REGEN, Mina. Sexualidade e deficiência: rompendo o silêncio.

Expressão e Arte Editora. São Paulo, 2005.

SILVA, Tatiane Santos.; LANDIM, Myrna Friederichs; SOUZA, Verônica dos Reis Mariano. A utilização de recursos didáticos no processo de ensino e aprendizagem de ciências de alunos com deficiência visual. Revista Electrónica de Enseñanza de las Ciencias, v. 13, n. 1, p. 32-47, 2014. Disponível em:

http://reec.uvigo.es/volumenes/volumen13/REEC_13_1_3_ex710.pdf Acesso em: 06 set. 2021. 
SIQUEIRA, Vera Helena Ferraz de; OLIVEIRA, Cristiane Maia de; BRAGA, Júlio Oliveira. O cinema e a formação docente: um diálogo sobre as questões de gênero. Comunicação \& Educação, Ano X, n. 2, maio-ago., 2005. Disponível em:

http://www.revistas.usp.br/comueduc/article/view/37523/40237 Acesso em: 06 set. 2021.

\footnotetext{
${ }^{\mathrm{i}}$ A práxis nesse artigo é compreendida como a prática entrelaçada à reflexão, desse modo, no contexto pedagógico, o conhecimento se estabelece a partir da partilha reflexiva das vivências, compreensões de mundo, dinâmicas e contradições vividas.

ii Ao longo do texto optamos por utilizar ambas as flexões de gênero (masculino e feminino) ou palavras neutras, isso porque o trabalho busca ser inclusivo para pessoas com deficiência visual, e caso alguma deseje utilizar leitores de texto os mesmos não reconhecerão outras flexões, a exemplo do "e" ou "x" no lugar de "o" ou "a".

iii Desenho universal se refere à produção de materiais, objetos e espaços que possam ser utilizados pelo maior número de pessoas possível, independentemente de suas particularidades.
} 